\title{
Analysis of Water Cycle in Weizhou Island of Beihai City, Guangxi Province, Part I: Theory and Model Parameter Identification
}

\author{
Zhang Shunfü ${ }^{1,2, a}$, Liu Changjun ${ }^{1,2}$, Li Chuanke ${ }^{3}$, Long Sili ${ }^{3}$, Zhou Jian ${ }^{4}$ and Zhang Qiyi ${ }^{1,2}$ \\ ${ }^{1}$ China Institute of Water Resources and Hydropower Research, Beijing, 100038, China \\ ${ }^{2}$ Research Center on Flood\&Drought Disaster Reduction of the Ministry of Water Resources, Beijing, 100038, China \\ ${ }^{3}$ Guangxi Water\&Power Design Institute, Nanning, Guangxi Province, 530023, China \\ ${ }^{4}$ Northwest Institute of Ecology and Environmental Resources, Chinese Academy of Sciences, Lanzhou, Gansu Province, 730000, China
}

\begin{abstract}
Groundwater is almost the unique source of water for Weizhou Island. Groundwater overexploitation has caused the groundwater level gradually dropping these years, causing many environmental problems such as seawater intrusion. On the basis of previous water resources survey and the understanding of the water cycle of Weizhou Island, the precipitation-runoff and variable-density groundwater flow analysis model in Weizhou Island was established. Model parameters were identified by historical rainfall and groundwater level data.
\end{abstract}

\section{Introduction}

Weizhou Island is an isolated island in Beihai city, Guangxi Province. Rainfall is the most important source of freshwater resources for the island. Due to the lack of surface water protection, the water quality there is not up to standard and the groundwater has become the main drinkable fresh water resource. In recent years, overexploitation of groundwater on the island has caused groundwater level gradually dropping, causing many environmental problems. Since 2009, the island's water supply has experienced severe water shortages, especially during the tourist season from July to October. The concentrated groundwater exploitation in the waterrich Pingdingshan area has formed an elliptical cone of depression around the mining wells. From 1999 to 2012, the groundwater level of the observation wells in the whole island showed a decreasing trend. Blind and unreasonable concentrated mining of groundwater has forced the groundwater level drop too much, might leading to local dryness of the wetlands, or even seawater intrusion which causes ecological deterioration and directly affecting regional economic development, resulting in loss of industrial and agricultural output value.

The shortage of fresh water resources and unreasonable development and utilization has become the bottleneck of the development of Weizhou Island. The tourism, industrial and agricultural development are all constrained by the lack of water resources. However, due to the lack of understanding on the circulation process of surface water and groundwater in Weizhou Island, no scientific planning scheme for rational utilization of water resources on the island was proposed,

\footnotetext{
a Corresponding author: zhangsf@iwhr.com
}

which restricted the construction of water conservancy infrastructure. To this end, based on the understanding of the water cycle process in Weizhou Island, this study aims to quantitatively study climate change and human activities by establishing a surface water-groundwater circulation model and identifying model parameters based on historical data. Through this study, a model basis is provided for the development of a reasonable groundwater exploitation plan to prevent overexploitation of aquifers leading to groundwater depression and seawater intrusion, thus promoting groundwater level recovery, maintaining ecosystems, and strengthening the region's ability to adapt to climate change and human activities.

\section{Control equation and discretization}

The density of seawater is different from the density of fresh water because of the influence of dissolved substances. The governing equation is the water flow mass conservation equation, the density state equation and the solute transport equation.

\subsection{Variable density groundwater control equation}

Regardless of the influence of temperature, the head is represented by an equivalent fresh water head, and the numerical calculation is carried out in consideration of the influence of the density gradient. The relationship between the equivalent freshwater head and the pressure head is [1]: 


$$
h_{f}=\frac{p}{\rho_{f} g}+x_{3}
$$

The variable density groundwater flow equation based on the equivalent freshwater head is as follows:

(1)Liquid flow equation

$$
\frac{\partial}{\partial x_{i}}\left[\rho k_{i j}\left(\frac{\partial h_{f}}{\partial x_{j}}+\frac{\rho-\rho_{f}}{\rho_{f}} \frac{\partial x_{3}}{\partial x_{j}}\right)\right]=\rho S_{f} \frac{\partial h_{f}}{\partial t}+\theta E \frac{\partial C}{\partial t}-\rho_{s} q_{s}
$$

(2)Density state equation

$$
\rho=\rho_{f}+E C ; E=\frac{\partial \rho}{\partial C}
$$

(3)solute transport equation

$$
\frac{\partial(\theta C)}{\partial t}=\frac{\partial}{\partial x_{i}}\left(\theta D_{i j} \frac{\partial C}{\partial x_{j}}\right)-\frac{\partial\left(\theta v_{i} C\right)}{\partial x_{i}}-q_{s} C_{s}
$$

In the equations, $x_{i}(i=1,2,3)$ represents the three coordinate axes of the cartesian coordinate system, $x_{3}$ is the same or opposite to the direction of gravity; $k_{i j}(i, j=1,2,3)$ is the permeability matrix, $\mathrm{L} / \mathrm{T} ; \rho$ is the density of groundwater, $\mathrm{M} / \mathrm{L}^{3} ; \rho_{f}$ is the density of fresh water, $\mathrm{M} / \mathrm{L}^{3} ; S_{f}$ is the water storage rate, $\mathrm{L}^{-1} ; t$ represents the time, $\mathrm{T} ; \theta$ a is effective porosity, which is dimensionless; $E$ is the relationship constant between groundwater density and freshwater density, $E \approx 0.7143 ; C$ is the concentration of dissolved substances, $\mathrm{kg} / \mathrm{L}^{3} ; q_{\mathrm{s}}$ is the volume of the aquifer source/sink item per unit time, $\mathrm{T}^{-1} ; \rho_{s}$ is the density of dissolved substances in the source and sink, $\mathrm{M} / \mathrm{L}^{3}$, $\rho_{s}=\rho[\xi(1-\theta)+\zeta \theta], \quad \xi=\frac{1}{1-\theta} \frac{\partial \theta}{\partial P_{N}}, \quad \zeta=\frac{1}{\rho} \frac{\partial \rho}{\partial P_{N}} ;$ $D_{i j}(i, j=1,2,3)$ is the hydrodynamic diffusion coefficient matrix, $\mathrm{L} / \mathrm{T} ; \quad v_{i}(i=1,2,3)$ is the groundwater flow velocity in the $x_{i}$ direction, $\mathrm{L} / \mathrm{T}$.

\subsection{Boundary conditions and initial conditions}

The first type of boundary condition, the boundary condition of the head (Dirichlet Boundary)

$$
\left.h_{f}\right|_{\Gamma_{1}}=h_{f 1}\left(x_{i}, t\right)
$$

The second type of boundary condition (Neumann Boundary), the fixed flow boundary condition

$$
-\left.k_{i j} \frac{\partial h_{f}}{\partial x_{j}} n_{i}\right|_{\Gamma_{2}}=q_{n}
$$

Initial conditions $\left.h_{f}\right|_{t=0}=h_{f 0}\left(x_{i}, 0\right)$.

In the equation, $h_{f 1}\left(x_{i}, t\right)$ is a known water head function, $\mathrm{L}$; $\quad n_{i}(i=1,2,3)$ is the cosine of the normal direction outside the seepage boundary, dimensionless; $\Gamma_{1}$ is the first type of seepage boundary condition; $\Gamma_{2}$ is the second type of seepage boundary condition; $q_{n}$ is normal flow, positive when outflow, $\mathrm{LT}^{-1} ; \lambda$ is the rainfall infiltration coefficient, dimensionless; $R$ is the rainfall intensity, $\mathrm{LT}^{-1} ; \quad h_{f 0}\left(x_{i}, 0\right)$ is the initial time head function, L. According to the information available, December 1999 is selected as the start point. Subsequent calculation of seepage and evaluation of water resources is derived on this basis.

\subsection{Solution}

The SEAWAT software is used to solve the problem, and the finite difference method is used to discretize the governing equation [1].

\section{Overview of Weizhou Island}

Weizhou Island is located on the sea surface of Beibu Gulf in the south of Guangxi Beihai City. It is $39 \mathrm{~km}$ away from Beihai City. The land area of the island is $24.74 \mathrm{~km}^{2}$. It ranges from $109^{\circ} 05^{\prime}$ to $109^{\circ} 13^{\prime}$ in longitude and from $20^{\circ} 54^{\prime}$ to $21^{\circ} 09^{\prime}$ in latitude. The average annual rainfall on the island is $1376.5 \mathrm{~mm}$, mainly concentrated in May to October, accounting for more than $80 \%$ of the annual rainfall. The average annual evaporation intensity is $1822.9 \mathrm{~mm}$. The Pingding Mountain area in the center of this island is dominated by red soil and has strong groundwater recharge capacity. It is also the main supply area for groundwater in the whole island. There are no long-term rivers on the island. In the north, west and east of the island, springs are exposed in low-lying areas, forming a number of small streams. The water flows along the gullies into the sea, forming a perennial stream.

According to the drilling data of Weizhou Island, Weizhou Island is roughly divided into a submerged layer, a weak aquifer, and a confined water layer (Figure $1)$. The confined water layer is subdivided into three layers from top to bottom: The first pressurized water layer, the second confined water layer and the third confined water layer. The rainfall is replenished to the diving layer through infiltration, and the submerged island replenishes the underlying confined water through the weak aquifer, while the confined water near the shore replenishes the submersible layer. At the same time, in the edge of the island, a number of holes have been exposed to salt water at different depths, and the groundwater system is a freshwater lens that floats on the sea.

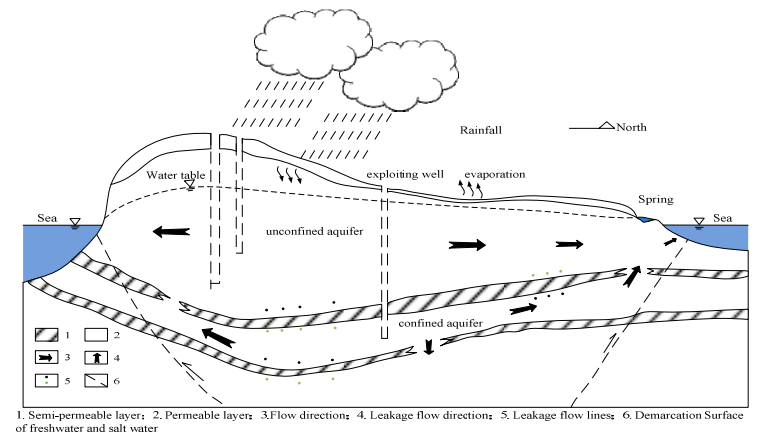

Figure 1. Groundwater flow pattern (from Zhong Zhenfu, Jiang Tonggen) [2]. 


\section{Identification of model parameters}

The identification and verification of the model mainly follows the following principles: (1) The simulated groundwater flow field is basically consistent with the actual groundwater flow field, in other words, the groundwater simulation contour is required to be similar to the measured groundwater level contour; (2) The simulated groundwater The dynamic process should be basically similar to the measured dynamic process, and the simulated and measured groundwater level process line shape is similar; (3) From the equilibrium point of view, the simulated groundwater equilibrium change is basically consistent with the actual situation; (4) The identified hydrogeology parameters are to be combined with actual hydrogeological conditions.

\subsection{The parameter identification method}

The parameter identification methods are divided into manual and automatic ones. The manual one depends on the professional experience or expert knowledge of the modeler. The process is cumbersome and subjective, and the automatic rate determination technology based on the optimization principle is efficient and objective [3]. The PEST software is based on Gauss-Maquardt-Levenberg (GML) developed by Doherty is an excellent representative of automatic calibration model[4]. Compared with other parameter estimation methods, its calculation efficiency is high, and only a small number of iterations (generally less than 30) is needed to approach the optimal value [4]. Moreover, PEST is connected with the input and output files of the simulation model, so there is no need to change the structure and source code of the original model. This feature makes the PEST model widely used for parameter identification and uncertainty estimation of various models [4-6]. PEST software has a relatively successful application in the identification of groundwater model parameters [7-8]. After comprehensive consideration, PEST software is used as a tool for parameter identification in this study.

\subsection{Model parameter zoning}

The parameters to be identified mainly include the rainfall infiltration coefficient and the hydrogeological parameters of each layer (including permeability coefficient, specific yield, storage coefficient, etc.). The zoning of the rainfall infiltration coefficient is shown in Figure 2. The zoning of the hydrogeological parameters of each layer are shown in Figure 3(a) to 3(e).

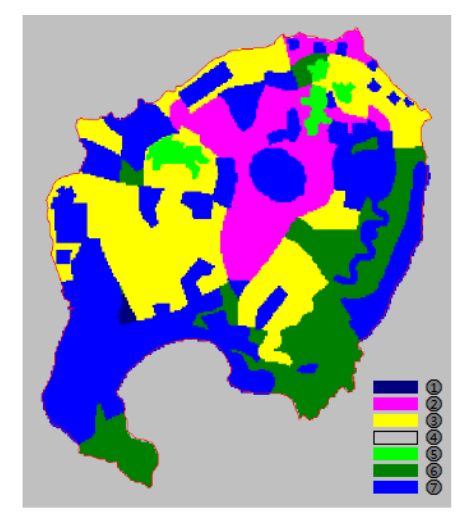

Figure 2. Zoning of rainfall infiltration on Weizhou Island.

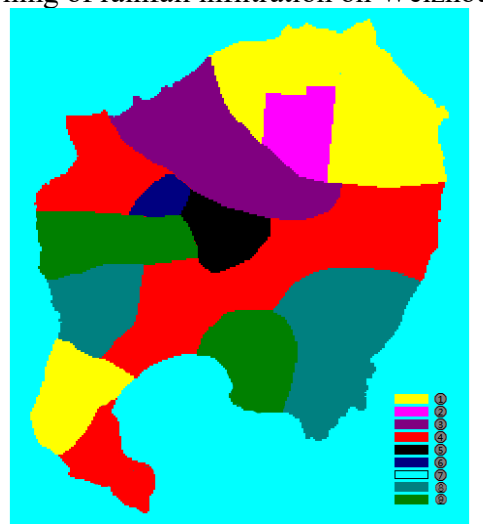

Figure 3(a). Zoning of hydrogeological parameters in unconfined aquifer.

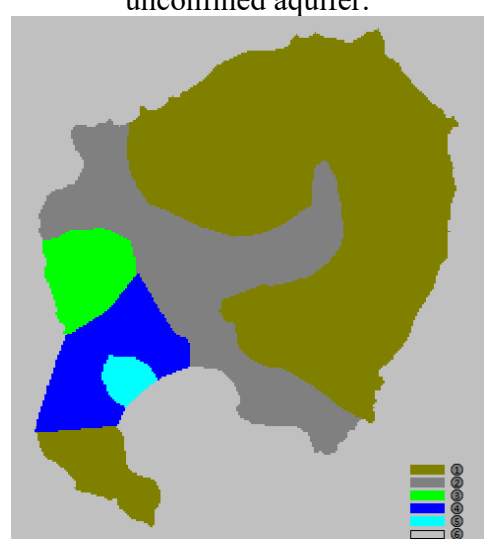

Figure 3(b). Zoning of hydrogeological parameters in weak

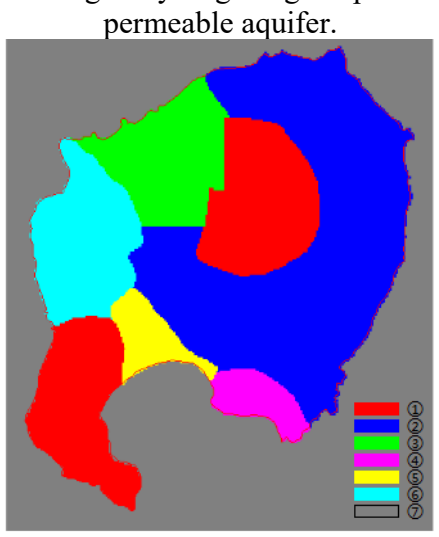

Figure 3(c). Zoning of hydrogeological parameters in the first confined aquifer. 


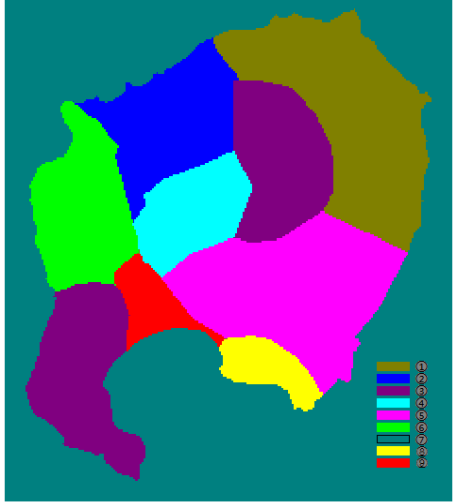

Figure 3(d). Zoning of hydrogeological parameters in the second confined aquifer.

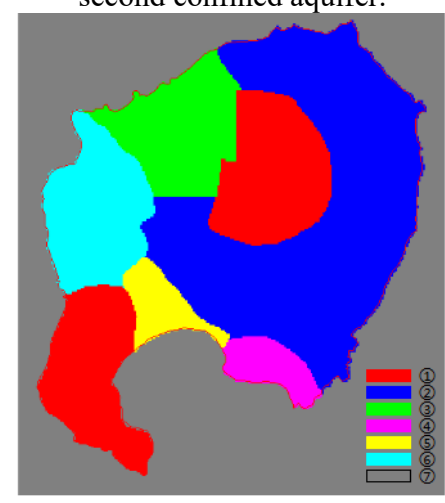

Figure 3(e). Zoning of hydrogeological parameters in the third confined aquifer.

\subsection{Observation well information}

The simulation period is from January 2000 to December 2013. The water level of 12 observation wells with relatively complete water level data is selected as the water level reference value for parameter determination. The position of the observation well is shown in Table 1 .

Table 1. Observation Well Information Table (Projected Coordinates: WGS_1984_UTM_Zone_49N).

\begin{tabular}{|c|c|c|c|c|}
\hline No. & Name & $\boldsymbol{x}_{\mathbf{1}}$ & $\boldsymbol{x}_{\mathbf{2}}$ & aquifer \\
\hline 1 & BS026 & 302661 & 2328373 & Unconfined \\
\hline 2 & BS033 & 304609 & 2330489 & Unconfined \\
\hline 3 & B44 & 302378 & 2328949 & Unconfined \\
\hline 4 & B45 & 303304 & 2328474 & Unconfined \\
\hline 5 & BD7 & 305950 & 2329224 & First confined \\
\hline 6 & WC3 & 301728 & 2326847 & Weak permeable \\
\hline 7 & BD8 & 305214 & 2328153 & Unconfined \\
\hline 8 & WC1-2 & 303305 & 2328839 & First confined \\
\hline 9 & H1-1 & 305010 & 2326483 & First confined \\
\hline 10 & CK927 & 301569 & 2328822 & Second confined \\
\hline 11 & CK930 & 304216 & 2328052 & Second confined \\
\hline 12 & WC5 & 303307 & 2328876 & Second confined \\
\hline
\end{tabular}

\subsection{Analysis of simulation results}

The comparison between simulation and observation for 12 wells are shown in Figures 4(a) to 4(1).

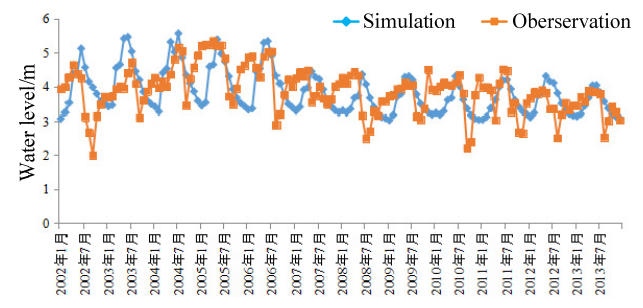

Figure 4(a). Water level comparison for well BD7.

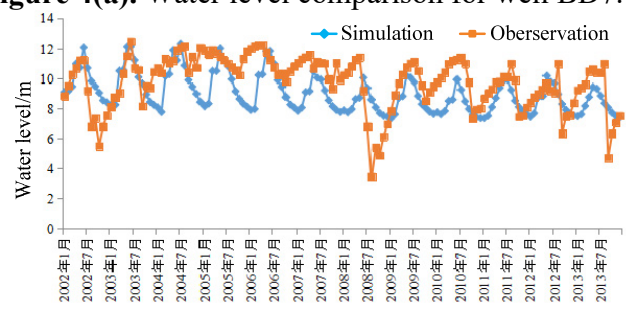

Figure 4(b). Water level comparison for well B44.

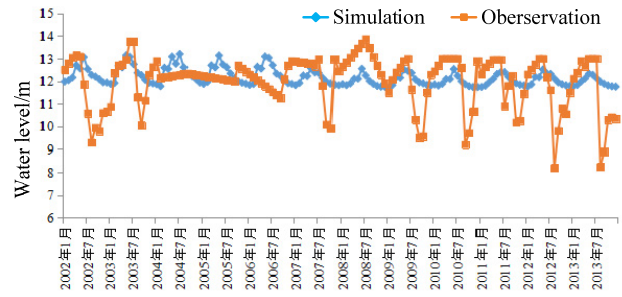

Figure 4(c). Water level comparison for well B45.

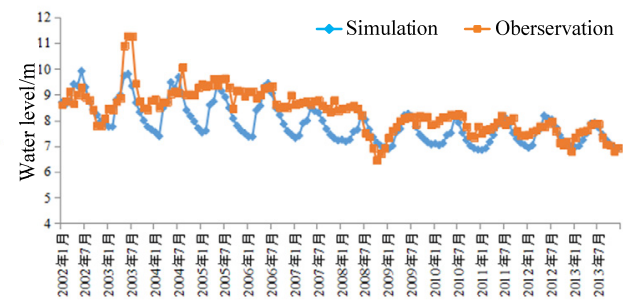

Figure 4(d). Water level comparison for well WC5.

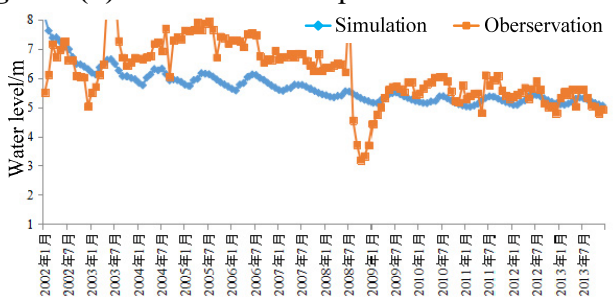

Figure 4(e). Water level comparison for well WC1-2.

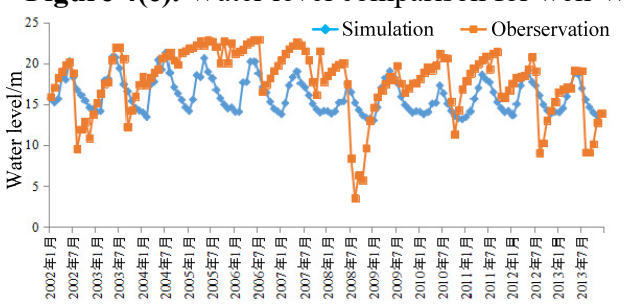

Figure 4(f). Water level comparison for well BD8. 


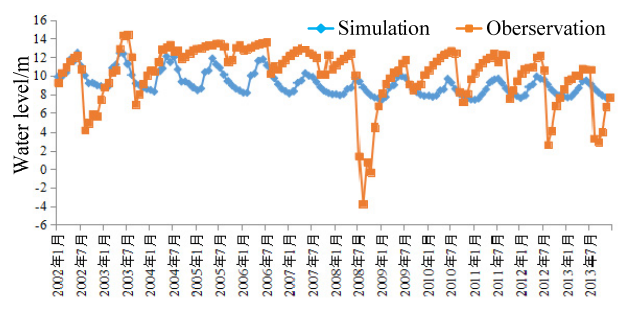

Figure 4(g). Water level comparison for well CK930.

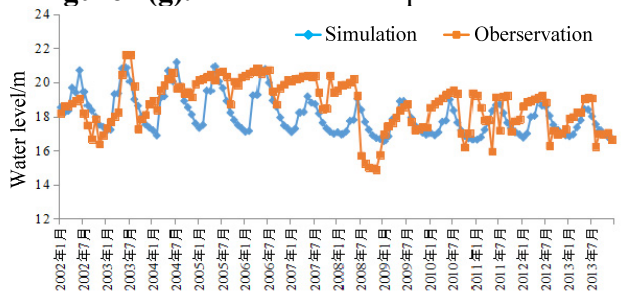

Figure 4(h). Water level comparison for well H1-1.

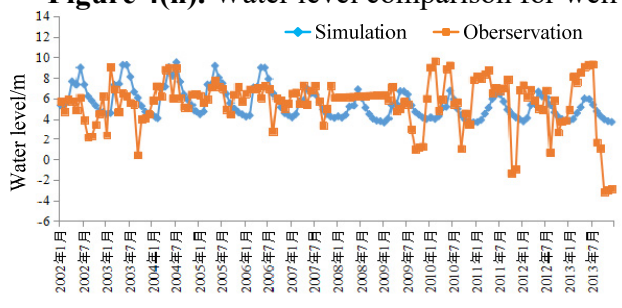

Figure 4(i). Water level comparison for well CK927. $\rightarrow$ Simulation $\rightarrow$-Oberservation

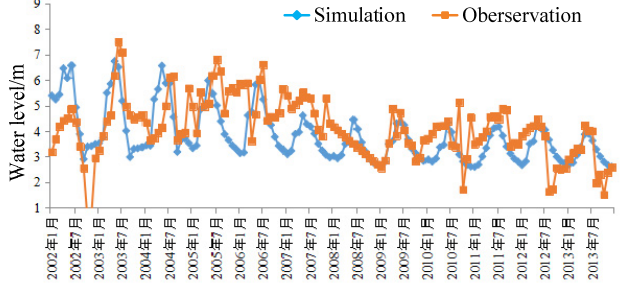

Figure 4(j). Water level comparison for well WC3.

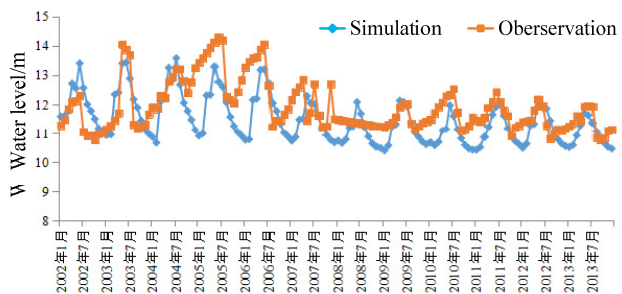

Figure 4(k). Water level comparison for well BS026.

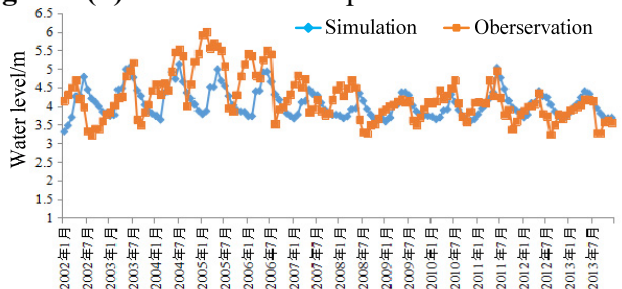

Figure 4(I). Water level comparison for well BS033.

It can be seen from Figure 4 that the calculated water level from 2002 to 2013 is the same as the approximate trend of the observed water level. Except for a certain error in some time periods, the total fitting trend of the water head at each point is good, which indicates the model parameters after identification. It can correctly reflect the actual situation of groundwater movement and seawater intrusion in Weizhou Island. The identified parameters are shown in Table 2 to Table 7.

Table 2. identified rainfall infiltration coefficient.

\begin{tabular}{|c|c|c|c|c|}
\hline Zone No. & (1) & (2) & (3) & (4) \\
\hline Chractereristic & $\begin{array}{c}\text { Park/green } \\
\text { land }\end{array}$ & $\begin{array}{c}\text { Shrub } \\
\text { land }\end{array}$ & Orchard & Sea \\
\hline$\alpha$ & 0.41 & 0.3 & 0.28 & 0.0 \\
\hline Zone No. & (5) & (6) & \multicolumn{2}{|c|}{$(7)$} \\
\hline Chractereristic & Lake & woodland & $\begin{array}{c}\text { Population } \\
\text { concentration }\end{array}$ \\
\hline$\alpha$ & 1.0 & 0.25 & \multicolumn{2}{|c|}{0.17} \\
\hline
\end{tabular}

Table 3. Hydrogeological parameters of the unconfined aquifer after identification. (m. $\mathrm{d}^{-1}$ for permeability coefficient)

\begin{tabular}{|c|c|c|c|c|c|c|c|c|c|}
\hline No. & (1) & (2) & (3) & (4) & (5) & (6) & (7) & (8) & (9) \\
\hline$k_{11}$ & 22.2 & 1.26 & 1.62 & 3.1 & 28.4 & 10.1 & 1.0 & 0.98 & 4.92 \\
\hline$k_{22}$ & 22.2 & 1.26 & 1.62 & 3.1 & 28.4 & 10.1 & 1.0 & 0.98 & 4.92 \\
\hline$k_{33}$ & 2.22 & 0.13 & 0.16 & 0.31 & 2.84 & 1.01 & 0.11 & 0.098 & 0.49 \\
\hline$S_{\mathrm{y}}$ & 0.151 & 0.051 & 0.035 & 0.050 & 0.017 & 0.012 & 0.01 & 0.094 & 0.13 \\
\hline
\end{tabular}

Table 4. Hydrogeological parameters of weak aquifer after identification $\left(\mathrm{m} \cdot \mathrm{d}^{-1}\right.$ for permeability coefficient).

\begin{tabular}{|c|c|c|c|c|c|c|}
\hline No. & (1) & (2) & (3) & (4) & (5) & (6) \\
\hline$k_{11}$ & 1.09 & 5.4 & 9.38 & 8.26 & 1.16 & 2.23 \\
\hline$k_{22}$ & 1.09 & 5.4 & 9.38 & 8.26 & 1.16 & 2.23 \\
\hline$k_{33}$ & 0.11 & 0.54 & 0.94 & 0.83 & 0.12 & 0.223 \\
\hline$S_{\mathrm{s}}\left(10^{-3}\right)$ & 0.112 & 3.17 & 2.85 & 0.0512 & 0.15 & 1.0 \\
\hline
\end{tabular}

Table 5. Hydrogeological parameters of the first confined aquifer after identification (m.d $\mathrm{d}^{-1}$ for permeability coefficient).

\begin{tabular}{|c|c|c|c|c|c|c|c|}
\hline No. & (1) & (2) & $(3)$ & (4) & (5) & (6) & (7) \\
\hline$k_{11}$ & 1.4 & 0.56 & 19.65 & 9.6 & 1.44 & 0.59 & 2.24 \\
\hline$k_{22}$ & 1.4 & 0.56 & 19.65 & 9.6 & 1.44 & 0.59 & 2.24 \\
\hline$k_{33}$ & 0.14 & 0.06 & 1.9 & 0.96 & 0.154 & 0.059 & 0.224 \\
\hline$S_{\mathrm{s}}\left(10^{-3}\right)$ & 0.074 & 0.13 & 3.87 & 2.76 & 1.7 & 0.074 & 1.0 \\
\hline
\end{tabular}

Table 6. Hydrogeological parameters of the second confined aquifer after identification (m. $\mathrm{d}^{-1}$ for permeability coefficient).

\begin{tabular}{|c|c|c|c|c|c|c|c|c|c|}
\hline No. & (1) & (2) & $(3)$ & (4) & (5) & (6) & $(7)$ & (8) & (9) \\
\hline$k_{11}$ & 0.72 & $\begin{array}{c}24.6 \\
5\end{array}$ & 0.11 & 0.1 & 0.16 & 1.09 & 2.24 & 9.6 & $\begin{array}{c}0.11 \\
4\end{array}$ \\
\hline$k_{22}$ & 0.72 & $\begin{array}{c}24.6 \\
5\end{array}$ & 0.11 & 0.1 & 0.16 & 1.09 & 2.24 & 9.6 & $\begin{array}{c}0.11 \\
4\end{array}$ \\
\hline$k_{33}$ & 0.72 & 2.5 & $\begin{array}{c}0.01 \\
4\end{array}$ & 0.01 & $\begin{array}{c}0.15 \\
6\end{array}$ & 0.11 & $\begin{array}{c}0.22 \\
4\end{array}$ & 0.96 & 0.01 \\
\hline $\left.\begin{array}{c}S_{\mathrm{s}}(10 \\
-3\end{array}\right)$ & $\begin{array}{c}0.01 \\
4\end{array}$ & $\begin{array}{c}0.05 \\
2\end{array}$ & $\begin{array}{c}0.05 \\
3\end{array}$ & $\begin{array}{c}0.03 \\
4\end{array}$ & $\begin{array}{c}0.01 \\
7\end{array}$ & $\begin{array}{c}0.12 \\
4\end{array}$ & 1.0 & $\begin{array}{c}0.27 \\
6\end{array}$ & 0.17 \\
\hline
\end{tabular}

Table 7. Hydrogeological parameters of the third confined aquifer after identification (m. $\mathrm{d}^{-1}$ for permeability coefficient).

\begin{tabular}{|c|c|c|c|c|c|c|c|}
\hline No. & (1) & (2) & (3) & (4) & (5) & (6) & (7) \\
\hline$k_{11}$ & 5.8 & 0.89 & 19.65 & 9.6 & 5.84 & 1.09 & 2.24 \\
\hline$k_{22}$ & 5.8 & 0.89 & 19.65 & 9.6 & 5.84 & 1.09 & 2.24 \\
\hline$k_{33}$ & 0.58 & 0.09 & 1.9 & 0.96 & 0.58 & 0.109 & 0.224 \\
\hline$S_{\mathrm{s}}\left(10^{-3}\right)$ & 3.24 & 0.94 & 3.87 & 2.76 & 1.7 & 8.2 & 1.0 \\
\hline
\end{tabular}




\section{Conclusion}

For Weizhou Island overexploitation of groundwater leads to falling water level and causing the problem of seawater intrusion. Based on the previous water resources survey data and the understanding of the water cycle law of Weizhou Island, the analysis model of precipitation-runoff and variable-density groundwater flow in Weizhou Island was established, and the model parameters were identified by historical data of rainfall and groundwater level. Identifying the model parameters will provide a basis for the next step to develop a reasonable groundwater exploitation plan, which will help prevent over-exploitation of aquifers and cause groundwater intrusion and seawater intrusion, promote groundwater level recovery, maintain ecosystems, and strengthen this region's capacity to adapt to climate change and human activities.

\section{Acknowledgments}

This paper was jointly supported by National Key R\&D Program of China (Mechanism of Landslide due to Seepage in expansive soil bank slope and dam;2017YFC1501201), Key R\&D Program of Guangxi(Study on Modeling and Joint Operation of Surface Water/Groundwater Circulation in Weizhou Island, Beihai City, Guangxi, JZ0202112016), Hunan Water Science \&Technology Plan(Research on flash flood simulation and forecasting methods based on Geomorphologic Hydrological Response Unit in Hunan mountainous areas; Hunan Water Science \& Technology Plan[2017]230-35); Key R\&D Program of Beijing (Beijing 2018 Annual Mountain Flood Disaster Prevention Project - Monitoring and Early Warning Platform and Monographic Study;JZ0203112018); Science \& technology project of Guangxi Water Resources Department (Development and application of dam safety management information system for Guangxi reservoir, 201614) and National Key R\&D Program of China (Research on key technologies and relevant equipments for emergency risk-elimination and quick repairment of flood discharge structures in the south to North Water Transfer Project, 2017YFC0405004).

\section{References}

1. Guo, Weixing, and Langevin, C.D., User's Guide to SEAWAT: A Computer Program for Simulation of Three-Dimensional Variable-Density Ground-Water Flow: Techniques of Water-Resources Investigations Tallahassee,Florida: US Geological Survey.1-87(2002)

2. The determination of the boundary of confined aquifer extending under the sea by analysis of groundwater level fluctuations. Li Guomin, Chen Chongxi. Earth Science-Journal of China University of Geosciences. 16 581-589(1991)

3. Boyle D P, Gupta H V, Sorooshian S. Toward improved calibration of hydrologic models:
Combining the strengths of manual and automatic methods [J]. Water Resources Research, 36(12): 3663-3674(2000)

4. Doherty J. PEST: Model-independent parameter estimation and Uncertainty Analysis, User manual: 7th ed [EB/OL]. Brisbane, Queensland, Australia:Watermark Numeric Computing(2018)

5. Iskra I, Droste R. Application of non-linear automatic optimization techniques for calibration of HSPF [J]. Water Environment Research, 79(6): $647-$ 659(2007)

6. Skahill B E, Baggett J S, Frankenstein S, et al. More efficient PEST compatible model independent model calibration[J]. Environmental Modelling \& Software, 24(4): 517-529(2009)

7. Meyer S C, Lin Y F, Roadcap G S. A hybrid framework for improving recharge and discharge estimation for a three-dimensionalgroundwater flow model [J]. Ground Water, 50(3): 457-463(2012)

8. Manskopf T, Braxein A, von Schwarzenberg $\mathrm{T}$. Large Scale Groundwater Modelling and Calibration [M]. Geoecology and Computers. Leiden: AA Balkema Publishers: 503-507(2000) 